\title{
Humor Creator and the Audience - A Multi-dimensional Model Supported by In-vivo Methodology
}

\author{
Varda Inglis, ${ }^{1, *}$, Sima Zach ${ }^{1}$, Shlomo Kaniel ${ }^{2}$ \\ ${ }^{1}$ Zinman College of Physical Education and Sport Sciences, Wingate Institute, Netanya, Israel \\ ${ }^{2}$ School of Education, Bar-Ilan University,Tel Aviv, Israel \\ *Corresponding author: vardai@wincol.ac.il
}

Received June 05, 2014; Revised June 15, 2014; Accepted July 04, 2014

\begin{abstract}
The purpose of this study was to reevaluate the multi-dimensional model of humor creation, which is comprised of three dimensions: humor motivation, humor cognition, and humor communication, using in vivo (natural setting) methodology. Thirty-four lecturers from colleges and universities completed a questionnaire. Additionally, 1530 students observed these lecturers and evaluated their sense of humor. Judges also evaluated the degree of humor in 750 video clips excerpted from 91 filmed lessons taught by the lecturers. Two path-analysis models substantiated the multidimensional model. A person's role - humor creator or humor receiver - was the strongest variable explaining the variance in humor creation. This study suggests that not only the humor creator, but also the humor receiver, contributes to variance in humor creation. In addition, the study expands the toolbox of humor measurement.
\end{abstract}

Keywords: in vivo methodology, humor, humor creation, humor evaluation, humor creator, humor receiver, social phenomenon, Israel

Cite This Article: Varda Inglis, Sima Zach, and Shlomo Kaniel "Humor Creator and the Audience - A Multidimensional Model Supported by In-vivo Methodology.” American Journal of Educational Research, vol. 2, no. 7 (2014): 503-512. doi: 10.12691/education-2-7-12.

\section{Introduction}

Humor is a social phenomenon that includes both humor creation and humor appreciation. People laugh and joke much more when they are with others than when they are alone (Martin \& Kuiper, 1999; Provine \& Fisher, 1989). Humor is defined as the ability to perceive the relationship between incongruous things in an ingeniously humorous manner and to convey it as a message to others. Humor appreciation, also called humor detection, is defined as "getting the joke" by attempting to comprehend disparities between the punch line and prior experience, which is the cognitive dimension of humor (Brownell, Hiram, Dee, Powelson \& Gardner, 1983), and as "enjoying the joke", which is the emotional dimension of humor (Gardner, Ling, Flamm \& Silverman, 1975) and has been related to the receiver, namely the listener, who reacts with laughter or a smile (Feingold \& Mazzella, 1993). In fact, appreciating or evaluating humor is not necessarily related to humor creation. People can enjoy humor without having the ability to create it (Kohler \& Ruch, 1996).

Traditionally, humor was explained by four classic theories: the psychoanalytic theory (Freud, 1960), the reversal theory (Apter, 1991, 2001; Wyer, 2004), the incongruity theory (Koestler, 1964; Ritchie, 2001, Suls, 1983), and the superiority/disparagement theory (Gruner, 1978, 1997). In addition to these theories humor research has taken other approaches, including the motivational (Cline, Altsech, \& Kellaris, 2003; Zweyer, Velker \& Ruch, 2004), the cognitive (Kruger, 1996; Norrick, 1986, 2003), the communicative (Booth-Butterfield \& BoothButterfield, 1991), and the personality trait (Cann \& Calhoun, 2001; Johnson \& McCord, 2010; Martin 2007; Saroglou \& Scariot 2002; Vernon et al. 2008) approaches.

Based on these divergent approaches, Feingold and Mazzella (1993) presented a multidimensional conceptual model of wittiness for humor creation, comprising three dimensions: humor motivation, humor cognition, and humor communication. Humor motivation is a situation or event that leads one to a certain behavior. People may create humor for several reasons, such as seeking laughs and amusement from others (Cline et al., 2003); reacting to a given situation experienced by the humor creator, such as coping with pain (Zweyer et al., 2004); responding to sarcasm or belittlement, or as a means of coping with stressful situations (Feingold \& Mazzella, 1993; Lefcourt, 2001; Martin, 1998); internalizing social norms (Meyers, 2000); or giving indirect criticism (Jorgensen, 1996; Zajdman, 1995). During debates, humor creators sometimes want to change the atmosphere, in order to better communicate or to improve the mood of others (Bippus, 2003; Bippus \& Dunbar, 2011). Bippus identified additional motives for humor creation in debates: to change the subject, to make up for a lack of debating skills, to dissipate hostility, and to create intimacy.

Humor cognition is a cognitive process in which the individual perceives a connection between two 
incongruous concepts or actions. Humor cognitive activity occurs when one listens to and tries to understand oral humor, and when one creates humor. In both cases the person perceives humor or absorbs humor through humor reasoning ability (Feingold \& Mazzella, 1991).

Humor communication is made up of verbal and nonverbal messages that elicit laughter and are unique to people who have an ability to choose, create, and time humor (Booth-Butterfield \& Booth-Butterfield, 1991). According to Feingold and Mazzella's model (1993), these three components activate each other when humor is created. "At a given time and place, an individual may or may not be motivated to produce humor. If the motivation exists, the person may or may not be capable of generating humor (whether original or recalled). Finally, if a humorous thought is conceived, it may or may not be communicated” (Feingold \& Mazzela, 1993, p. 440).

However, how humor is created, what is needed to create effective humor, and what reciprocal relationships exist between the humor creator and the humor receiver, are questions that have been examined predominantly through laboratory studies using in vitro methodology (e.g., Feingold \& Mazzella, 1993; Turner, 1980). In this controlled experimental methodology, only reliable and valid tools are used to analyze specific variables. To do so, the researcher has to create an environment in the laboratory that imitates the natural setting. In contrast, in vivo methodology examines the reality in a natural setting, relating not only to discrete variables but also to relationships among variables, people, and the environment.

Although the leading conceptual model proposed by Feingold and Mazzella (1993) has often been explained and quoted (see, e.g., Galinkin, 2000; Martin, 1998), it has never been adequately substantiated. Most research conducted to confirm the theories about and approaches to humor, including the Feingold and Mazzella model, pertained to the humor creator or the humor listener, to humor evaluation, and to theme preferences, but did not measure the spontaneous humor so prevalent in everyday life (see Gruner, 1997; Martin \& Kuiper, 1999; Provine 2000; Provine \& Emmorey 2006; Ziv \& Gadish 1990). Moreover, only a handful of studies have been conducted in a natural setting (e.g., Mehu \& Dunbar, 2008; Robinson \& Smith-Lovin 2001).

Given that humor is generally created in a natural setting or social situation, it is important to apply research about humor creation in a natural setting. Therefore, there is no wonder that in vitro methodology that was applied in Feingold and Mazzella (1993)'s study, could not by itself substantiate their model. Further, the measurement instruments used in this approach are insufficient not only because they merely imitate reality, but also because they are not comprehensive; they consider only the humor creator and not the humor receiver (Latour, 2000). Following the recommendations of Dunbar (2001) and Howrigan and MacDonald (2008), we suggest that since humor is a social phenomenon that occurs spontaneously in a natural setting, it should be studied by in vivo methodology, using observational instruments tailored to such a setting.

Hence, the purposes of this study were: 1 ) to construct new instruments to measure humor dimensions in a natural setting; 2) to examine both the humor creator's and the humor receiver's aspects in all study examinations. We hypothesized that Feingold and Mazzella's multidimensional theory for humor creation will be validated when investigated with an "in vivo" approach. Also, there will be correlation between the variables: Humor motivation, humor cognition, and humor communication, and between the variables and humor creation. In addition, we hypothesized that the multidimensional theory for humor creation will be expanded to include personality traits as an additional part of the theory.

\section{Methods}

\subsection{Participants}

\subsubsection{Lecturers}

Thirty-four lecturers from nine colleges and universities were sampled, 28 of whom were identified by their students as "having a sense of humor" and six as "not having a sense of humor". Their demographic characteristics were as follows: 22 males and 12 females; age 32-66 $(\mathrm{M}=48)$; years of education 16 to $30(\mathrm{M}=$ 21.27); 9.4\% were professors, $62 \%$ held $\mathrm{PhD}$ degrees, 18.8\% MAs, 6.3\% BAs, and 2.4\% held no academic degree. Fourteen were lecturers in the social sciences, four in nature sciences, one in education, two in physical education, and eight in the humanities; one was a law professor and four were mathematicians. Twenty-six were married, six were divorced, and two were unmarried.

Table 1. Study instruments and their characteristics

\begin{tabular}{|c|c|c|}
\hline Variable & Instrument & Purpose \\
\hline Humor creation & $\begin{array}{c}\text { 1Humor sociometric } \\
(1.2)\end{array}$ & $\begin{array}{c}\text { To examine lecturers' sense } \\
\text { of humor by students }\end{array}$ \\
\hline Humor creation & $\begin{array}{c}\text { Judges evaluating } \\
\text { teacher's } \\
\text { humor by observing } \\
\text { lessons } \\
(1.1)\end{array}$ & $\begin{array}{l}\text { To evaluate humor events } \\
\text { created in real lessons, } \\
\text { according to humor } \\
\text { quantity, students' } \\
\text { reactions, and humor } \\
\text { quality } \\
\end{array}$ \\
\hline Motivation & $\begin{array}{l}\text { Students' evaluation } \\
\text { of lecturers' } \\
\text { motivation for humor } \\
\text { (2) }\end{array}$ & $\begin{array}{c}\text { To receive students' } \\
\text { evaluations of lecturers' } \\
\text { motivation through } \\
\text { observation }\end{array}$ \\
\hline \multirow[t]{2}{*}{ Cognition } & $\begin{array}{l}\text { Lesson observation } \\
\text { (3.1) }\end{array}$ & $\begin{array}{c}\text { To examine if the lecturer } \\
\text { succeeded in identifying } \\
\text { clues for humor }\end{array}$ \\
\hline & $\begin{array}{c}\text { Students evaluating } \\
\text { cognition of lecturers } \\
\text { humor (3.2) }\end{array}$ & $\begin{array}{c}\text { To receive students' } \\
\text { evaluation of humor } \\
\text { cognition through } \\
\text { observation }\end{array}$ \\
\hline \multirow[t]{2}{*}{ Communication } & $\begin{array}{l}\text { Lesson observation } \\
\text { (4.1) }\end{array}$ & $\begin{array}{c}\text { To assess humor } \\
\text { characteristics (mimicry, } \\
\text { body language, intonation) }\end{array}$ \\
\hline & $\begin{array}{l}\text { Students' evaluating } \\
\text { communication of } \\
\text { lecturers' humor (4.2) }\end{array}$ & $\begin{array}{c}\text { To receive students' } \\
\text { evaluation of humor } \\
\text { communication by lecturer } \\
\text { through observation }\end{array}$ \\
\hline Personality & $\begin{array}{c}\text { The Big Five } \\
\text { Personality Inventory } \\
\text { (BFI) (McCrae and } \\
\text { John 1992) (5) }\end{array}$ & $\begin{array}{c}\text { To examine other } \\
\text { personality characteristics } \\
\text { and their relations to level } \\
\text { of humor creation }\end{array}$ \\
\hline
\end{tabular}

\subsubsection{Students}

The demographics of the 1530 students enrolled in classes given by the lecturers participating in this study were as follows: $35.6 \%$ males and $64.4 \%$ females, age $18-$ 
$67(\mathrm{M}=26.83)$. Mean years of education was 13.80 ; $74.3 \%$ were unmarried and the rest were married. Seventy-six percent were undergraduate students, $16.4 \%$ had BA degrees, $4.3 \%$ MAs, and the rest other degrees. Sixty-seven percent majored in education and physical education, $13.2 \%$ in the natural sciences, $6 \%$ in humanities, $11.4 \%$ in law, $2 \%$ in arts, $2 \%$ in engineering, $2 \%$ in accounting, and $1.8 \%$ in medicine.

\subsection{Instruments}

Eight in vivo instruments were used to measure Feingold and Mazzella's (1993) three dimensions of humor as well as the additional dimension of personality traits. Six in vitro instruments were also used in the research, but are not reported here due to article's focus considerations. A summary of the in vivo instruments and their characteristics is presented in Table 1. A description of each instrument follows the table.

\subsubsection{Humor Creation}

To assess the lecturer's level of humor creation, two instruments were used: 1) Observation of lessons and evaluation by judges and 2) observation and evaluation of the teachers' humor by students (Humor Sociometric) (Ziv 1979).

Observation of lessons. Observation of videotaped lessons was used to measure several variables of humor creation. Studies that analyzed the laugh reaction to a humoristic phenomenon showed that the students' laugher expressed the existence of a humorous situation (Deckers, 1993; Long \& Graesser, 1988). Based on these findings, we identified humor episodes according to the students laugh at the end of a story that was told by the teacher, or event that happened during the lesson. The researcher observed these humor episodes again and created video clips. The following measures were taken from the humor episode clips: The quantity of lecturer humor creation was assessed by the number of humoristic events per specified time (the lesson). Humorous films were observed by two judges who evaluated the humor on a 5-point scale (1 = not funny; 5 = very funny). Judges used the following criteria: 1) timing and relevancy; 2) cognitive level incongruence, absurdity, and surprise; and 3) level of amusement - communication with the audience, intonation, and body language. Similar criteria were used in a study by Bippus (2003). Cronbach alphas for these criteria ranged from. 66 to. 89. An average was calculated for all humoristic events for each participant. Inter-judge reliability was. 903.

Humor sociometric (Ziv 1979). This instrument is an in vivo peer evaluation instrument. Students were asked to evaluate their lecturer's sense of humor in a questionnaire. The instrument included a 5-point scale. In addition, students were asked to choose which of the following descriptions best characterized their lecturer: 1) tells familiar jokes; 2) improvises from situations and discussions; 3) laughs at jokes and humor of students; 4) laughs with students about funny situations; and 5) imitates characters. Only those chosen on items 2, 3, and 5 were considered as humor creators. Scoring was on 5point scale ( $1=$ no sense of humor; $5=$ a very high sense of humor). An average score was calculated for each lecturer based on the scores given by his/her students. The original developer of the instrument reported correlations between humor creation and humor sociometric tests, ranging from. 38 to. 68 ( $\mathrm{p}<.05)$, and reliability scores of. 78-.83 (p <. 01) after a two-month interval (Ziv, 1979).

\subsubsection{Humor Motivation}

Evaluation of humor motivation of the lecturers was obtained by the students' evaluation of lecturers' motivation to create humor. Students attending the lectures evaluated the lecturers' motivation for humor creation after observing the lesson. Students were given a questionnaire consisting of 5 items taken from the "Motivation for Humor Test" and "Motivation for Humor in Teaching Test," which were created for this study. Each item was evaluated according to the following factors: situation in the lesson (e.g., teacher used humor to recapture students' attention), social motivation (e.g., teacher liked to impress his/her students by using humor), reinforcing learning (e.g., teacher used humor so that his/her students will remember the subject matter), and anxiety reduction (e.g., teacher used humor to relax the students after telling them they were going to have a test). Each item was scored on a 5-point Likert scale. The reliability was Cronbach alpha -. 818.

\subsubsection{Humor Cognition}

Humor cognition was assessed by observing the ability of the lecturer to locate cues from the environment to create humor. Two judges observed humoristic segments from a videotaped lesson to measure the teacher's ability to locate cues of humor, which is the ability to locate two unrelated concepts or events and use them to create humor. This ability was tested for each humoristic segment. The judges determined and coded the teachers' ability to locate humoristic cues from their surroundings ( $0=$ unable to locate; 1 = able). Each teacher was evaluated on this ability by summing the points received for this measure. For example, while the teacher was talking about the philosopher Schopenhauer, the door was suddenly opened, and his reaction was: here Schopenhauer comes to visit. In this example, the teacher created humor by combining a cue from the subject matter with a cue from the class environment.

Students' evaluation of the teachers' cognitive humor. The purpose of this measure was to obtain the observing students' assessment of the cognitive dimension of the teachers' humor. The students assessed the teacher's cognitive humor by filling out a questionnaire after watching a lesson. The students assessed the cognitive components described by the following items on a scale of 1-5 (1= low; 5 = high): 1 ) "The teacher is using situation that happens in class to tell jokes"; 2) "The teacher wants to impress the students with his humor"; 3) "The teacher is using terms with no connection in the same joke"; 4) "The teacher repeats jokes that he told in previous lessons"; 5) " The teacher likes to invent new jokes". Maximum Likelihood with Varimax rotation Factor Analysis was carried out with Eigen value greater than 1 . (2.414) Loadings of the cognitive items were:. 416,. 501,. 423,. 460,. 429 respectively. Reliability to the aggregated five items using Cronbach's alpha was. 729.

\subsubsection{Humor Communication}


Humor communication was assessed using a structured observation of the communication components in humor (movement, facial expression, intonation). Observation of humoristic segments in a video-taped lesson was used to test the following communication components: 1) Joketelling time, measured in seconds; 2) Number of changes in vocal intonation. Studies of intonation indicate that a change of three tones of pitch creates intonation, and speech is composed of many series of intonations separated by pauses (Cook, 2002; Scherer, Banse, \& Walbott, 2001). While speaking, this information is of utmost importance in conveying emotional states as the main portion of the verbal message. Thus, changes in intonation affect communication between the humor creator and the humor receiver, and therefore represent the humor communication of the person using it; 3) Number of gestures (hand, leg, head), and number of facial expressions. Studies have shown that $55 \%$ of non-verbal communication entails facial expressions. While humor may sometimes be created when the wrong facial expression or no facial expression is used to match the words presented (North, Todorov \& Osherson, 2010), in most cases when facial expressions do not match speech, the message is not transmitted (Geles, 2006). Thus, gestures and facial expressions are important in humoristic communication and its evaluation. Correlation was calculated between the number of changes in intonation relatively to the duration of humor episode, and the number of gestures and facial expressions relatively to the duration of humor episode. Since the correlation was high $(r=.866)$, one index - the lecturer's communication - was established by calculating the average of the two variables.

Students' evaluation of the teacher's humor communication (reprocessed from Wanzer, BoothButterfield \& Booth-Butterfield, 1995). The purpose of this instrument was to obtain the students' evaluation of the lecturer's communication through humor. The students evaluated the teachers' humor communication on a 5point scale ( $1=$ low; $5=$ high) for the following statements: "This person is very funny;" "This person is skilled in telling jokes;" "This person tells jokes better than any person I know;" "This person's behaviors are funny;" "This person makes me laugh;" and, "This person has a good sense of humor" (Wanzer et al., 1995). In the preliminary study the observers were asked to explain their answers, and these answers helped in shaping the final statements for testing the properties of communication used by the lecturers. The range of scores was the average of the students' answers to the ten statements, on a scale of 1-5 (1=low; $5=$ =high). Internal consistency of the observers' scoring rated. 93 according to Cronbach's Alpha (Wanzer et al., 1995). Based on factor analysis, 10 of the questions in the student questionnaire in the current study were determined to be representative of the lecturers' humor communication. Reliability coefficient (Cronbach's Alpha) was. 828. $($ Eigen value $=5.883)$.

\subsubsection{Personality Traits}

Thirty four teachers filled out The Big Five Personality Inventory (BFI) (McCrae \& John, 1992). The BFI is a self-report questionnaire used to examine personality characteristics and their relation to the participants' level of humor creation and the model variables. The inventory is comprised of 44 items characterizing behaviors and traits. The participant completes sentences on a 5-point scale ( $1=$ do not agree at all; $5=$ completely agree) that begin: "I see myself as a person that...". The completion of these sentences characterizes the participants' personality according to five traits: 1) Extraversion - this factor is basically Eysenck's concept of Extraversion/Introversion; it relates to traits such as being sociable, gregarious, assertive, talkative, enthusiastic, and active; 2) Emotional stability - the opposite of the trait Neuroticism. The scale is associated with being anxious, depressed, angry, embarrassed, emotional, worried, or insecure, or their opposite. Here higher scores on the trait indicated the "positive" side of the trait; 3) Agreeableness - (contrasted with Antagonism or Hostility) includes being courteous, flexible, trusting, good-natured, cooperative, forgiving, soft-hearted, warm, and tolerant; 4) Conscientiousness (Dependability) - associated with being careful, thorough, responsible, organized, hardworking, preserving; it can be contrasted to Impulsivity; and 5) Openness to experience (also called Culture or Intellect) refers to being imaginative, curious, original, broad-minded, intelligent, and artistically sensitive. The other side of this trait refers to people who judge in conventional terms and favor conservative values (McCrae and John 1992). There are 8-9 items describing each trait. The score of each trait is the average for all the items in that trait. Reliability coefficients (Cronbach's Alpha) for all the measures of this test ranged from. 74 to. 95 (McCrae and John 1992). In this study the reliability coefficients of the five traits were:. 585,. 767,. 855,. 869, and. 850 respectively.

\section{Procedure}

Participants were lecturers and professors from nine colleges and universities. These participants were approached based on the recommendation of their students. Students were asked to recommend lecturers known either for their good sense of humor or for their lack of a sense of humor. In the second step, the first author sent a consent form to the recommended lecturers, asking them to participate in the study. In-vitro tests and questionnaires were administered to lecturers who agreed to participate in the study. In vivo aspects of this study included three characteristics: The venue of study episodes was the classroom where the usual teaching routine took place; the time of episodes was during the lesson and evolved from natural stimulations in the teaching environment; and, communication was established between the humor creator - the lecturer, and the humor receiver - the students.

\subsection{Data Gathering}

Lecturers were filmed with a video camera that was focused on them during the entire lesson. Each lecturer was filmed during one, two, or three lessons. Ninety-one filmed lessons were observed. Humor segments in these films were identified by laugh reactions from the students. The segments were copied to a computer using Ulead Video Studio video software. A different file was opened for each lecturer and for each lesson. From the 91 filmed lessons, 750 humor segments were identified. The 
duration of most lessons was 90 minutes. Seventy different subjects were taught. The number of humor segments in a lesson ranged from 0 to 24 .

\subsection{Observation - Data Processing}

The following measures were taken from observed humor video-clips: The exact time in the lesson that the humor segment appeared; the duration of the segment in seconds; whether the lecturer identified clues from the environment, and from where; whether humor evolved from the lecturer's memory or was new; Number of intonation changes during the humoristic talk/story; number of changes in the lecturer's body gestures and movements during the humoristic talk/story (the number of changes in intonation and number of body movements were calculated relative to the length of humor episode); and judges' objective ranking of the humoristic segments.

\subsection{Data Analyses}

A series of correlations were calculated in order to examine the relationships between the various multidimensional model variables referring to the lecturers' humor creation. Using AMOS software version 17 , we conducted path analysis to test the hypothesis that humor creation is related to personality traits and to the three observed variables of Feingold and Mazzella's (1993) model: humor motivation, humor cognition, and humor communication. Using AMOS in a small sample size is questionable among professionals who use AMOS (see, MacCallum, Browne \& Sugawara, 1996; Weston \& Gore 2006). However, although our sample is small, it is based on other parameters that are extremely large: 750 humor clips and 1250 students (Central Limit Theorem) (Jackson, 2003). This article presents two models that were conducted: one for the students, and one for the judges. Exogenous variables were lecturers' personality traits. Three traits were not presented in the model, due to their negligible influence on the target variable. Endogenous variables were alienated into mediator variables - humor motivation, humor cognition, and humor communication, and the target variable - humor creation (Weston \& Gore 2006). The fit of the model was assessed with multiple indices: the chi-square, which would be non-significant for a good-fitting model; the comparative fit index (CFI), which should approximate unity; and the root mean square error of approximation (RMSEA), which should be smaller than 0.06 for a good-fitting model (Hu \& Bentler, 1995).

\section{Results}

This section first presents the means, SDs, and range of scores for study variables (see Table 2), the correlations among study variables, and path analyses of model variables and the differences between them. In addition, Maximum Likelihood with Varimax rotation Factor Analysis was carried out with Eigen value greater than 1 to 18 items questionnaire filled by 1530 students which confirmed the item related to each of the researched variable, namely: motivation, cognition, and communication.
Table 2. Means, SDs, and range of scores for study variables

\begin{tabular}{|c|c|c|}
\hline Variable & Instrument [Range] & $\begin{array}{l}\text { Means } \\
\text { (SDs) }\end{array}$ \\
\hline Humor creation & $\begin{array}{c}\text { Judges' scores } \\
{[1-5]}\end{array}$ & $2.64(.62)$ \\
\hline Humor creation & $\begin{array}{l}\text { Students' scores } \\
{[1-5]}\end{array}$ & $3.67(.81)$ \\
\hline Humor motivation & $\begin{array}{c}\text { Evaluation of humor motivation } \\
\text { (Students) } \\
{[1-5]}\end{array}$ & $3.03(.54)$ \\
\hline \multirow{2}{*}{ Humor cognition } & $\begin{array}{l}\text { Evaluation of humor cognition } \\
\text { (Students) [1-5] }\end{array}$ & $2.64(.51)$ \\
\hline & $\begin{array}{l}\text { *Finds clues from the environment } \\
\text { (Judges) }\end{array}$ & $\begin{array}{c}22.48 \\
(14.85)\end{array}$ \\
\hline \multirow{4}{*}{$\begin{array}{c}\text { Humor } \\
\text { communication }\end{array}$} & $\begin{array}{l}\text { Evaluating humor communication } \\
\text { [1-5] (Students) }\end{array}$ & $3.16(.62)$ \\
\hline & $\begin{array}{l}* * \text { Mean of communication } \\
\text { measures (Judges) }\end{array}$ & $\begin{array}{c}9.39 \\
(4.50)\end{array}$ \\
\hline & Extraversion & $3.38(.61)$ \\
\hline & Emotional stability & $2.99(.77)$ \\
\hline \multirow[t]{3}{*}{$\begin{array}{l}\text { Personality traits } \\
{[1-5]}\end{array}$} & Pleasantness & $3.36(.92)$ \\
\hline & Conscientiousness & $3.38(.91)$ \\
\hline & Experience openness & $3.37(.77)$ \\
\hline
\end{tabular}

Notes: *Finds clues from the environment: $\operatorname{Min}=2$; $\operatorname{Max}=50$;

**Mean of communication measures: $\operatorname{Min}=1.75$; $\operatorname{Max}=22.6$

The first aim of the study was to use new instruments to examine the multidimensional model of humor creation the relationship between motivation, cognition and communication as measured in a natural setting.

\subsection{Correlations among Model Dimensions}

A series of correlations were calculated for examining the relationships between the multidimensional model variables. First, in order to explore whether the model dimensions are involved in spontaneous humor, this study examined humor creation in a natural setting - a lecturer in class. New in-vivo instruments created for this study included judges' observations and students' observations. Inter-correlations among model dimensions and between them and humor creation were calculated by comparing this information to data obtained from the judges' observations. Results showed inter-correlations only between humor motivation and humor cognition ( $r=.36$; $p$ $<.05$ ). Additionally, correlations were found between humor creation and cognition $(\mathrm{r}=.46$; $\mathrm{p}<.01)$. These results demonstrate that humor cognition is important to the judges' evaluation of the lecturers' humor. Second, correlations between students' evaluation of lecturer humor and their evaluation of the model dimensions revealed high positive correlations with motivation $(\mathrm{r}=$. 83; $\mathrm{p}<.01)$, cognition $(\mathrm{r}=.78 ; \mathrm{p}<.01)$ and communication ( $\mathrm{r}=.88 ; \mathrm{p}<.01)$. Inter-correlations were also high and positive in motivation and cognition ( $\mathrm{r}=.82$; $\mathrm{p}<.01)$, motivation and communication ( $\mathrm{r}=.89 ; \mathrm{p}<.01)$, and cognition and communication ( $\mathrm{r}=.88$; $\mathrm{p}<.01$ ). Third, Pearson correlations were calculated to examine the relationships between humor creation in a natural setting students evaluating lecturer humor and judges observing and evaluating humor segments, and humor dimensions (see Table 3).

(1.1), (1.2), (2), (3.2), (4.2), (3.1), (4.1) = Instrument number, see Table 1 . 
As can be seen in Table 3, correlations between judges' evaluations and students' evaluation were significant.

Table 3. Pearson correlations among model dimensions in a natural setting $(n=33)$ Students' evaluation

\begin{tabular}{|c|c|c|c|c|c|}
\hline \multirow{4}{*}{ Judges' evaluation } & Variables & $\begin{array}{c}\text { Humor creation } \\
\text { (1.2) }\end{array}$ & Humor motivation (2) & Humor cognition (3.2) & Humor Communication (4.2) \\
\hline & Humor creation (1.1) & $.49 * *$ & $.47^{* *}$ & $.49 * *$ & $.54 * *$ \\
\hline & Cognition (3.1) & $.55^{* *}$ & $.54 * *$ & $.53^{* *}$ & $.59 * *$ \\
\hline & Communication (4.1) & $-.39 *$ & $-.35 *$ & -.20 & $-.36 *$ \\
\hline
\end{tabular}

\subsection{Examining new in Vivo Instruments Created for this Study}

Correlations were also calculated to examine the relationship between new instruments created for this study and the instruments used in Feingold and Mazzella's study (1993). Moderate correlations were obtained between judges' evaluations of humor segments and students' evaluations of lecturers' sense of humor, and in vitro tests for humor creation $(r=.382$; $\mathrm{p}<.05$; $\mathrm{r}=$. 403; $\mathrm{p}$ $<$. 05 respectively) (See Table 4 ). In vitro tests were examined in the study, but not reported in this article due to length constraints.

Table 4. Pearson correlations among model dimensions in laboratory tests and in a natural setting $(n=33)$

\begin{tabular}{|c|c|c|c|c|c|c|c|c|c|}
\hline & & \multicolumn{4}{|c|}{ Students' evaluation } & \multicolumn{4}{|c|}{ Judges' evaluation } \\
\hline & & 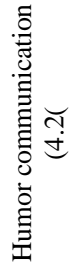 & 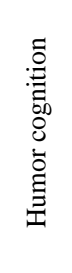 & 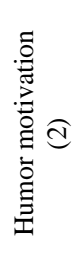 & 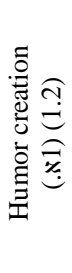 & 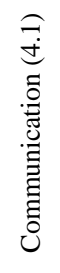 & 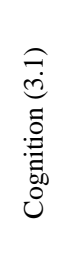 & 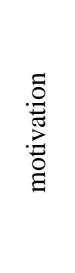 & 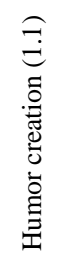 \\
\hline \multirow{4}{*}{ 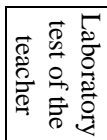 } & Humor creation & $.47 * *$ & $.35 *$ & $.46^{* *}$ & $.40^{*}$ & .08 & 38.* & .22 & 38.* \\
\hline & Humor motivation & $.45^{* *}$ & $.55^{* *}$ & $.40^{*}$ & .35 & 01. & 38.* & $.77 * *$ & .27 \\
\hline & Humor cognition & .21 & 06. & 17. & 06. & 04. & 07. & 05. & -.08 \\
\hline & Humor communication & $.37 *$ & .33 & 38. & 26. & -.17 & 26. & 27. & 23. \\
\hline
\end{tabular}

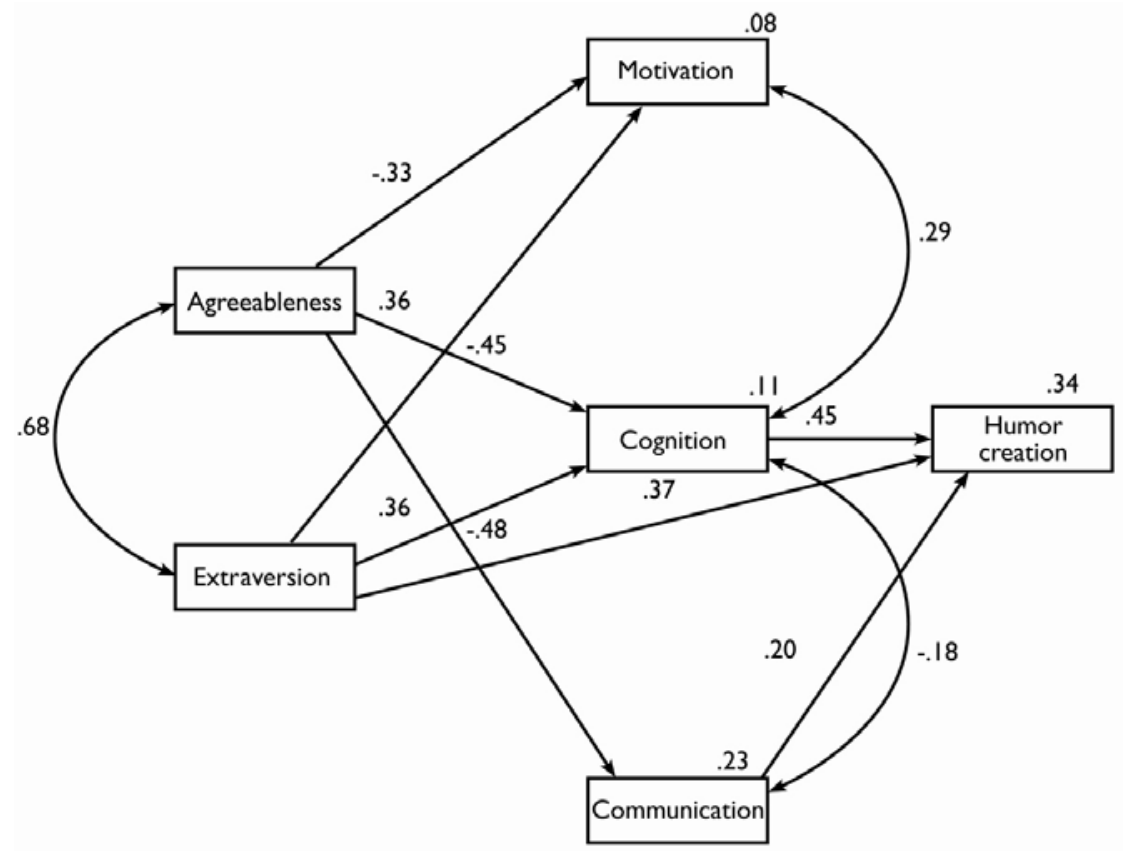

Figure 1. Relationships between Personality Traits and Model Variables as Mediators of Humor Creation according to the judges

Results also indicated non-significant correlations among the in vitro and in vivo judges, except for the motivation variable. Therefore, it can be concluded with caution that creating humor in the laboratory and creating humor in a natural setting are two related similar but not identical facets of humor phenomena.

\subsection{Model Summary according to Path Analyses}

Using AMOS software version 17, we conducted path analysis to test the hypothesis that humor creation is related to personality traits and to the observed three variables of Feingold and Mazzella's (1993) model: humor motivation, humor cognition, and humor communication. Exogenous variables were the lecturer's personality traits. Three traits were not presented in the model due to their negligible influence on the target variable. 
Endogenous variables were alienated into the mediator variables humor motivation, humor cognition, and humor communication, and into the target variable - humor creation (Weston \& Gore 2006).

Two models emerged: The first (see Figure 1) illustrates the best fit model in a natural setting, as measured by observation and the judges' evaluations. We followed $\mathrm{Hu}$ and Bentler's (1995) recommendations to reach the best-fit model. All goodness-of-fit indices of the model indicated an acceptable fit between the model and data: $\chi_{(4)}^{2}=.717, \mathrm{p}=.949$, NFI $=.986, \mathrm{TLI}=1.56, \mathrm{CFI}=$ 1.00, RMSEA $=$. 000. Figure 1 shows standardized estimates of the path coefficients in the model. The lines were significant paths at the $\mathrm{p}=0.05$ level.
A direct relationship between extraversion and agreeableness, as well as indirect relationships mediated by motivation, cognition, and communication to humor creation, were found. Motivation and cognition had direct relationships with humor creation, and no relationships were found between motivation and communication.

The second model (see Figure 2) illustrates the best fit model in a natural setting as measured by observation and students' evaluations. All goodness-of-fit indices of the model indicated an acceptable fit between the model and data: $\chi_{(6)}^{2}=6.787, \mathrm{p}=.341$, NFI $=.965$, TLI $=.984$, CFI $=.995$, RMSEA $=$. 063. Figure 2 shows standardized estimates of the path coefficients in the model. The lines were significant paths at the $\mathrm{p}=0.05$ level.

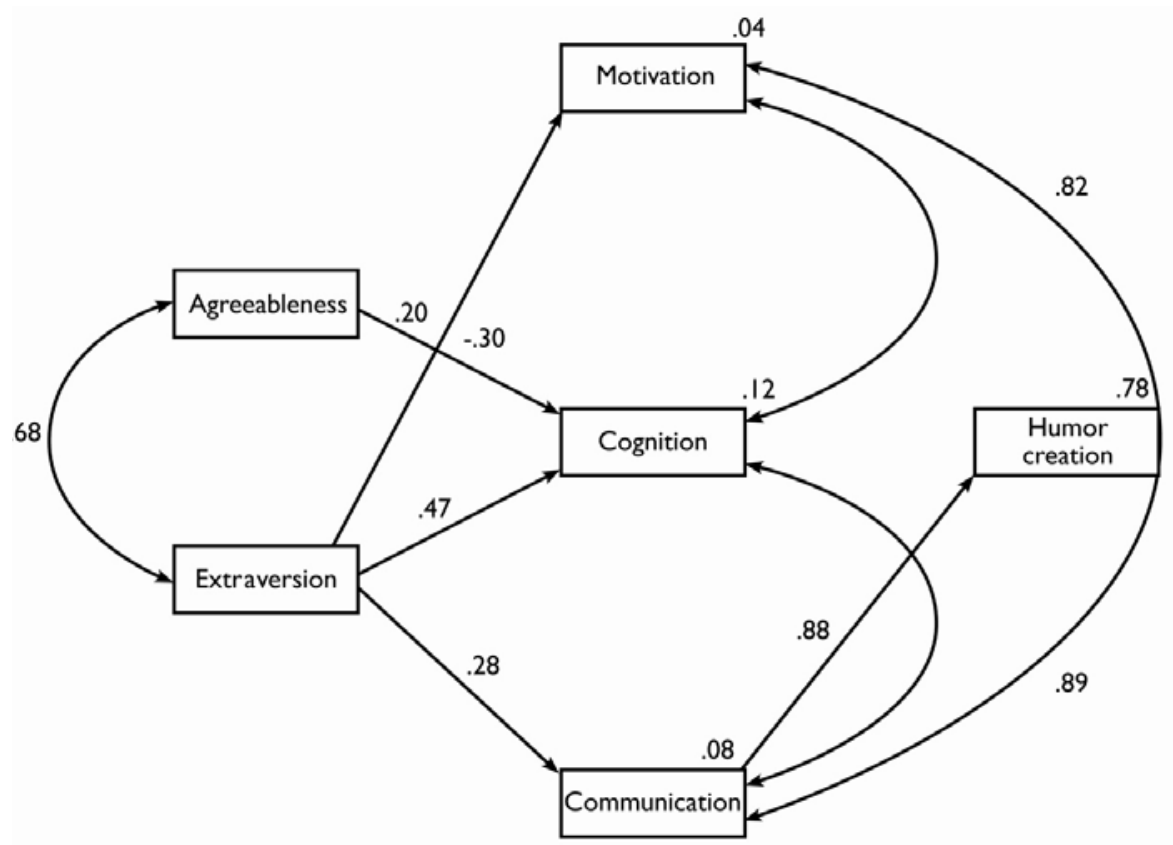

Figure 2. Relationships between Personality Traits and Model Variables as Mediators of Humor Creation according to the Students

According to this model, extraversion and agreeableness are indirectly related through the mediators' motivation and cognition. A direct relationship exists between communication and humor creation, and a strong relationship is observed within mediator variables. It can be seen that the contribution of communication to lecturer's humor creation was high according to the students.

To summarize: Path analysis revealed two relevant models for a natural setting where reciprocal relationships exist among the variables: 1) According to the judges, positive correlations existed between cognition, communication, extraversion, and humor creation; 2) According to the students, positive correlations existed between the three variables and the two personality traits agreeableness and extraversion, but only communication had a direct association with humor creation. This model supported the model asserting that for humor to be created, relationships between motivation, cognition, and communication (in that order) are needed. In each of the two models a different variable had the highest association with humor creation; in the judges' model, cognition scored highest, whereas in the students' model, communication had the direct highest association with humor creation.

\section{Discussion}

Significant correlations were found among research variables in a natural setting as measured by the new instruments. However, levels of correlations were moderate, indicating that each instrument measured different aspects of the study variables.

The multidimensional model was reinforced by two path analysis models: the judges' model and the students' model. These results are not in line with the results of Feingold and Mazzella's (1993), who measured humor using a laboratory methodology.

The results of the present study demonstrate that humor creation also depends upon the receiver's point of view. Cognition explained the variance of humor creation for the judges, who examined each and every humor segment, and the lecturer's humor communication explained the variance of humor creation for the observing students. Others have also reported that the teachers' communicative ability is perceived by students as an important component of the teachers' humor (e.g., Frymier, Wanzer \& Wojtaszczyk, 2007). Feingold and Mazzella (1993) measured communication using a self-report questionnaire that examined the participant's willingness 
to communicate with humor. We argue that such a questionnaire is only one part of the story, and although it may be important, it alone is not sufficient to measure human communication. Geles (2006) identified four codes of communication processed in the brain: voice and speech - which are processed vocally, and mimicry and body language - which are processed visually. In the current study we included these codes in the instruments created to measure communication.

The students' model clearly shows a relationship among the model variables and between communication and humor creation. This model also shows that motivation, cognition, and communication become mediator variables between personality traits and humor creation. From the students' viewpoint, communication is the most influential variable affecting the lecturer's humor creation.

The judges' model displays a direct relationship between extraversion and humor creation. The other four personality traits had indirect relationships with humor creation. As claimed by others (e.g., Howrigan \& MacDonald, 2008; Provine, 2000), the ability to produce, comprehend, and appreciate various forms of humor is a distinct cognitive ability. The current models also revealed that cognition was related to humor creation.

Further analysis revealed correlations between motivation, cognition, and communication, and humor creation, in both models, reinforcing the multidimensional model for humor creation in a natural setting. These correlations strengthen the notion that people with a sense of humor possess characteristics that are included in the multidimensional model for humor creation, and that the characteristics are interrelated.

Among all model variables, only communication, as measured by body language and intonation changes, was correlated with the five personality traits. The highest correlation was with emotional stability and agreeableness. Weaker correlations were found with the other three traits. In other words, the humor receiver receives the communication created by the creator, which also, as mentioned by Cook (2002), represents the creator's personality traits.

A differentiation between the three groups of participants in this study can be made according to the situation in which the humor took place and according to the participants within a specific social interaction. The students and the judges received the humoristic message, whereas the lecturers created it. Therefore, it is not surprising that the predictor variable of humor creation differed in each of the three groups of participants and in their situation when delivering or receiving humor: Motivation predicted the lecturer's humor creation, cognition predicted humor creation according to the judges - the humor receivers who evaluated each humor segment, and communication predicted humor creation according to the students - the humor receivers who evaluated humor by means of a general impression of the lecturer's humor in the class. These results also suggest that each instrument has a different focus and is probably sensitive to different aspects of humor.

The results of this study imply that communicative abilities have a greater influence on the humor receiver than the personality traits of the humor creator. In other words, individuals with personality traits such as emotional stability, extraversion, agreeableness, or conscientiousness may be unable to create humor and deliver it successfully because they lack the ability to communicate in a humorous way. It might also be that people can possess the appropriate personality traits to create and produce humor, but are unable to deliver it successfully because they lack the ability to communicate with humor. Another possible situation may occur where the humor creator does not "read" the audience, and so the humor created is not relevant, not timed, and therefore not funny (Merolla, 2006). Hence, it can be concluded that the ability to create humor depends both on personality traits that have been reinforced throughout the humor creator's life, and on the ability to communicate.

The following conclusions can be drawn from our study: First, the ratings received from the observations of students and judges were complementary; second, the variables that best predict evaluation of humor creation were dependent upon whether one is the humor receiver (cognition and communication) or the humor creator (motivation). Indeed, one of the important contributions of this study to the current knowledge of humor in teaching is that it demonstrated the distinction between the humor receiver and the humor creator; third, the humor creators created humor mainly due to their enhanced ability to communicate.

This study examined a humor model using in vivo methodology, and this is a contribution to humor analysis. In addition, the present study substantiated the multidimensional model of Feingold and Mazzella (1993). Results also indicated relationships between and among the model's variables.

\subsection{Recommendations}

Based upon the results of this study, we suggest a revised multi-dimensional model that is comprised of relations among study variables, taking both the humor creator and the humor receiver into consideration (see Figure 3).

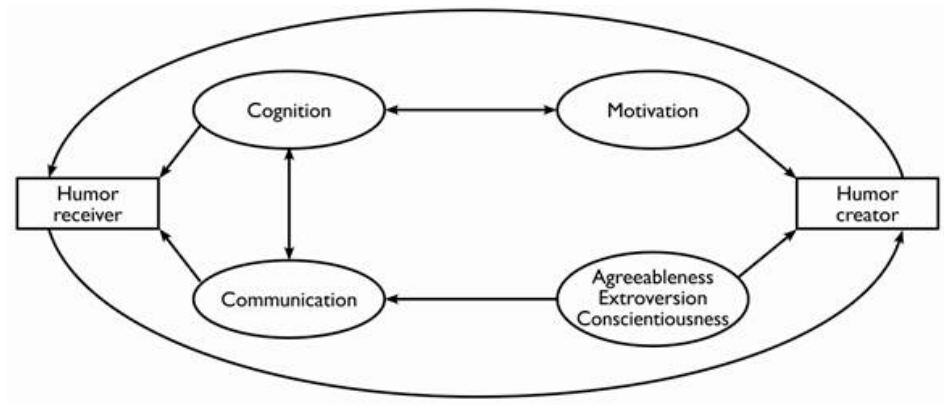

Figure 3. The Multidimensional Model for Apontaneous Humor Creation in a Natural Setting 
It is recommended that future research should work on reinforcing this suggested revision, and use both in vivo and in vitro methodologies to expand knowledge on the examined phenomena. In vivo methodology can identify the relevant variables to be examined in large-scale populations through in vitro methodology. In vivo methodologies, as Dunbar (2001) mentioned, can introduce new ideas and test them in a natural setting. As in the natural sciences, such an approach is warranted in the social sciences as well.

One research challenge could be to create valid instruments to measure humor variables in general and in a natural setting in particular. For example, documenting motivation for humor in a natural setting in teaching can be done by observing filmed humor segments immediately after the lesson, and asking the teacher what motivated him/her to produce humor in each segment.

The findings in the present study are subject to a number of limitations. First, the control group in this study was comprised of participants who were not experts in humor creation. Second, some lecturers who were aware that they lacked a sense of humor were not willing to participate in the study. Further, lecturers who did agree to participate but who did not communicate through humor provided a significantly smaller number of humor segments than did the participants with a sense of humor. Third, the correlations between humor motivation, humor cognition, and humor communication of students were high. This probably stems from the fact that the students' three questionnaires were combined together into one; we conducted a factor analysis on these merged questionnaires. Even though a few items were close in meaning we did not eliminate them, as suggested by the factor analysis results. This was done to keep the original questionnaires' items.

\subsection{Practical Implications}

This study contributes to a better understanding of the building blocks of humor and the relationships among them, both for the humor creator and the humor receiver. It can be concluded, albeit with a certain amount of caution that since humor is comprised of distinct components each one of them can be developed in order to create humor that can be appreciated. Many people from different domains such as education, medicine, theater, film making, media, public relations, and interpersonal relations can benefit from the idea that humor creation can be studied and perhaps improved through practice.

\section{References}

[1] Apter, M.J., (1991). A structural-phenomenology of play. In J. H. Kerr \& Michael J. Apter (eds.), Adult play: A reversal theory approach, (13-29). Amsterdam: Swets \& Zeitlinger.

[2] Apter, M.J., (Ed.). (2001). Motivational styles in everyday life: A guide to reversal theory. Washington, DC: American Psychological Association.

[3] Bippus, A.M. (2003). Humor motives, qualities, and reactions in recalled conflict episodes. Western Journal of Communication, 67, 413-426.

[4] Bippus, A.M. \& Dunbar, N.E. (2011, July). Partners' agreement about humor frequency and style. Paper presented at the International Society for Humor Studies Conference, Boston.
[5] Booth-Butterfield, S. \& Booth-Butterfield. M. (1991). Individual differences in the communication of humorous messages. Southern Communication Journal, 56, 205-218.

[6] Brownell, Hiram H., Dee Michel, John Powelson \& Howard Gardner. 1983. Surprise but not coherence: sensitivity to verbal humor in right-hemisphere patients. Brain Lang Usage, 18, 20-27.

[7] Cann, Arnie \& Lawrence G. Calhoun. 2001. Perceived personality associations with differences in sense of humor: Stereotype of hypothetical others with high or low senses of humor. Humor: International Journal of Humor Research, 14, 117-130.

[8] Cline, T. W., Altsech, M. B., \& Kellaris, J. J. (2003). When Does Humor Enhance Or Inhibit Ad Responses?: The Moderating Role of the Need for Humor. Journal of Advertising, 32, 31-46.

[9] Cook, N.D. (2002). Tone of voice and mind: The connections between intonation, emotion, cognition and consciousness. Amsterdam/Philadelpia: Cureton, E. E., John Benjamins Publishing.

[10] Deckers, L. (1993). On the validity of weight-judging paradigm for the study of humor. Humor: International Journal of Humor Research, 6, 43-56.

[11] Deckers, L. \& Buttram R.T. (1990). Humor as a response to incongruities within or between schemata. Humor: International Journal of Humor Research, 3, 53-64.

[12] Dunbar, K. 2001. What scientific thinking reveals about the nature of cognition. In K. Crowley, C.D. Schunn, \& Takeshi (Eds.). Designing for science: Implications from everyday classroom and professional settings, (115-140). Mahwah, NJ: Lawrence Elbaum.

[13] Feingold, A. \& Mazzella, R. (1991). Psychometric intelligence and verbal humor ability. Personality and Individual Differences, $12,427-435$.

[14] Feingold, A. \& Mazzella, R. (1993). Preliminary validation of multidimensional model of wittiness. Journal of Personality, 61, 439-456.

[15] Freud, S. (1960) [1905]. Jokes and their relation to the unconscious. New York: Norton.

[16] Frymier, A.B., Wanzer M.B. \& Wojtaszczyk, A.M. (2007, November). Assessing student perceptions of inappropriate and appropriate teacher humor. Paper presented at the Annual Convention of the National Communication Association, Chicago, Illinois, Retrieved from http://eric.ed.gov ED = 499080.

[17] Galinkin, M.B. (2000). The spontaneous humor production of four intellectually precoscious preschoolers: A window into the mind. Dissertation-Abstract International-Section A: Humanities and Social Science, 60, 2361.

[18] Gardner, H., Ling, P.K., Flamm, L., \& J. Silverman 1975. Comprehension and appreciation of humorous material following brain damage. Brain, 98, 399-412.

[19] Geles, L. (2006). How to read people according to their speech, voice, body and facial language. Translated from English by I. Miller \&. Kineret Zmora-Bitan, Dvir Publishers. Hebrew

[20] Gruner, C.R. (1978). Understanding laughter: The working of wit and humor. Chicago: Nelson-Hall.

[21] Gruner, Charles R. (1997). The game of humor: A comprehensive theory of why we laugh. New Brunswick, NJ: Transaction.

[22] Howrigan, D.P. \& MacDonald, K.B. (2008). Humor as a mental fitness indicator Evolutionary Psychology, 6, 652-666.

[23] Hu, L.T. \& Bentler, P.M. (1995). Evaluating model fit. In R.H. Hoyle (Ed.), Structural equation modeling. Concepts, issues, and applications, 76-99. London: Sage.

[24] Jackson, D. L. (2003). Revisiting sample size and number of parameter estimates: some support for the $\mathrm{N}: \mathrm{q}$ hypothesis. Structural Equation Modeling, 10 (1), 128-141.

[25] Johnson, A. \& McCord, D.M. (2010). Relating sense of humor to the Five Factor Theory personality domains and facets. American Journal of Psychological Research, 6, 32-40.

[26] Jorgensen, J. (1996). The function of sarcastic irony in speech. Journal of Pragmatics, 26, 613-634.

[27] Kohler, G. \& Ruch, W. (1996). Sources of variance in current sense of humor inventories: How much substance, how much method variance? Humor: International Journal of Humor Research, 9, 363-397.

[28] Koestler, A. (1964). The art of creation. London: Hutchinson.

[29] Kruger, A. (1996). The nature of humor in human nature: Crosscultural commonalties. Counseling Psychology Quarterly, 9, 235242.

[30] Latour, B. (2000). Pandora's hope: Essays on the reality of science studies. Cambridge, MA: Harvard University Press. 
[31] Lefcourt, H.M. (2001). Humor-The psychology of living buoyantly. New York: Kluwer Academic, Plenum.

[32] Long, D.L. \& Graesser. A.C. (1988). Wit and humor in discourse processing. Discourse Processes, 11, 35-60.

[33] MacCallum, R.C., Browne, M.W. \& Sugawara, H.M. (1996). Power analysis and determination of sample size for covariance structure modeling. Psychological Methods, 1, 130-149.

[34] Martin, R.A. (1998). Approaches to the sense of humor: An historical review. In W. Ruch (Ed.), The sense of humor, 15-60. Berlin, New York: Mouton de Gruyter.

[35] Martin, R.A. (2007). The psychology of humor: An integrative approach. London: Elsevier Academic Press.

[36] Martin, R.A. \& Kuiper, N.A. (1999). Daily occurrence of laughter: Relationships with age, gender, and Type A personality. Humor: International Journal of Humor Research, 12, 355-384.

[37] McCrae, R.R. \& John, O.P. (1992). An introduction to the fivefactor model and its applications. Journal of Personality, 60, 175215.

[38] Mehu, M. \& Dunbar, R.I.M. (2008). Relationship between smiling and laughter in humans (homo sapiens): testing the power asymmetry hypothesis. Folia Primatol, 79, 269-280.

[39] Merolla, A.J. (2006). Decoding ability and humor production. Communication Quarterly, 54, 175-189.

[40] Meyers, J.C. (2000). Humor as a double-edged sword: Four functions of humor in communication. Communication Theory, 10, 310-331.

[41] Norrick, N.R. (1986). A frame-theoretical analysis of verbal humor. Semiotica, 60, 225-245.

[42] Norrick, N.R. (2003). Issues in conversational joking. Journal of Pragmatics, 35, 1333-1359.

[43] North, M.S., Todorov, A. \& Osherson, D.N. (2010). Inferring the preferences of others from spontaneous, low-emotional facial expressions. Journal of Experimental Social Psychology. Available online 25 June 2010.

[44] Provine, R.R. (2000). Laughter: A scientific investigation. New York: Viking.

[45] Provine R.R. \& Emmorey, K. (2006). Laughter among deaf signers. Journal of Deaf Studies and Deaf Education, 11, 403-409.

[46] Provine, R.R. \& Fisher, K.R. (1989). Laughing, smiling, and talking: Relation to sleeping and social context in humans. Ethology, 83, 295-305.
[47] Ritchie, G. (2001). Current directions in computational humour. Artificial Intelligence Review, 16, 119-135.

[48] Robinson, D.T. \& Smith-Lovin, L. (2001). Getting a laugh: Gender, status, and humor in task discussions. Social Forces, 80, 123-158.

[49] Saroglou, V. \& Scariot, C. (2002). Humor styles questionnaire: Personality and educational correlates in Belgian high school and college students. European Journal of Personality, 16, 43-54.

[50] Scherer, K.R., Banse, R., \& Walbott, H.G. (2001). Emotion inferences from vocal expression correlate across languages and cultures. Journal of Cross-Cultural Psychology, 32, 76-92.

[51] Suls, J.M. (1983). Cognitive processes in humor appreciation. In P.E. McGee \& J.H. Goldstein (Eds.), Handbook of humor research, Vol. 1: Basic issues, 39-57. New York: Springer-Verlag.

[52] Turner, R.G. (1980). Self-monitoring and humor production. Journal of Personality, 48, 163-172.

[53] Vernon, P.A., Martin, R.A., Schermer, J.A. \& Mackie, A. (2008). A behavioral genetic investigation of humor styles and their correlations with the Big-5 personality dimensions. Personality and Individual Differences, 44, 1116-1125.

[54] Wanzer, M., Booth-Butterfield, M. \& Booth-Butterfield, S. (1995) The funny people: A source-orientation to the communication of humor. Communication Quarterly, 43, 142-153.

[55] Weston, R., \& Gore, P.A. (2006). A brief guide to structural equation modeling. The Counseling Psychologist. 34, 719.

[56] Wyer, R.S. (2004). Social comprehension and judgment: The role of situation models, narratives, and implicit theories. Mahwah, $\mathrm{NJ}$ : Lawrence Erlbaum Associates.

[57] Zajdman, A. (1995). Humorous face-threatening acts: Humor as strategy. Journal of Pragmatics, 23, 325-339.

[58] Ziv, A. (1979). Sociometry of humor: Objectifying the subjective. Perceptual and Motor Skills. 49, 97-98.

[59] Ziv, A., \& Gadish, O. (1990). The disinhibiting effects of humor: Aggressive and affective responses. Humor: International Journal of Humor Research, 3, 247-257.

[60] Zweyer, K., Velker, B. \& Ruch, W. (2004). Do cheerfulness, exhilaration, and humor production moderate pain tolerance? A FACS study. Humor: International Journal of Humor Research. 17, 85-119. 